\title{
PolicyMatters
}

Newsletter of the IUCN Commission on Environmental, Economic and Social Policy (CEESP)

\section{Globalisation and governance}

Matthias Finger

A four-day conference organised by CEESP in collaboration with the Social Science Research Council, New York, brought together leading thinkers on the subject of governance in August this year. The objective of Beyond Governance, which took place in Murree, Pakistan, was to apply an emerging understanding of governance to a concrete issue - within a regional context - in this case South Asia. Through a selection of papers and extracts of papers presented in Murree, Policy Matters examines the issue of governance from a number of different perspectives, leading with a critical examination of the concept of governance and its current uses, extracted from a longer paper by Professor Matthias Finger.

The special importance of both the concept and the practice of governance stems from the fact that globalisation has profoundly altered the premises of and the ground-rules for traditional nation-state politics. As traditional, local, national and international political institutions are no longer adequate to meet the challenges created by the process of industrial development, 'governance' emerges as a new concept, directly related to the process of globalisation.

Globalisation is defined here as the latest stage of a process where technological, economic, ecological, cultural, and military trends, traditionally observable on a geographically limited scale and scope, are extended to the entire globe. First separately, but increasingly in a synergistic manner - and therefore ever accelerating - these trends lead to the emergence of new players with new and different (power) relationships among them. Let me briefly comment here on each of these five trends separately.

Technological globalisation - which is the result of global scientific development - is certainly most fundamental, as this is the process which underlies and accelerates most if not all other processes, in particular those of economic and cultural globalisation. Key players are techno-scientific institutions, whose aim is to make scientific progress useful for commercial and political interests. As almost all of these institutions work with the same scientific rationality, the outcomes of technological globalisation are quite homogeneous.

The field of communication perfectly illustrates how technological globalisation influences cultural globalisation. Indeed, whether it is because of the media, communication or tourism, more and more inhabitants of the planet share the same cultural references and define themselves in respect to the same dreams, mostly American ones. This, of course, leads to a certain uniformity, as well as a loss of cultural diversity (e.g., Ritzer, 1998). However, this process of cultural globalisation is not necessarily synonymous with cultural homogenisation, since this new 'global culture' is often fragmented and incoherent, victim as it is of rapidly changing fads and fashions. The main actors here are media and entertainment conglomerates, which are in fewer and fewer hands. One must also mention that parallel to the standardisation of culture one can observe a localisation and so-called "ethno-isation" as a reaction to it.

It is in the area of economy and business that the phenomenon of globalisation has probably been best studied (e.g., Barnet \& Cavanagh, 1994; Dunning, 1993;), and often equated to globalisation per se. However, one must distinguish here between the globalisation of the financial networks (which are by now almost totally integrated), the alobalisation of production. and the alobalisation of the markets. i.e.. of consumption. As a consequence. the

Contents Contents Issue no. 6 December 1999

Governance issue Governance and globalisation

Matthias Finger

Structural adjustment in Pakistan

Shahrukh Rafi Khan

Criminal appropriations of power

Paula R. Newberg

Paving flagstones to Hell

Dipak Gyawali

Research project on

'comprehensive governance'

Matthias Finger

Regular features

CEESP contacts

Letter from the chair

New resources

Network news

Forthcoming

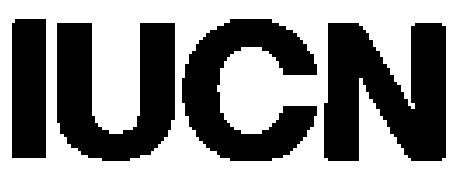

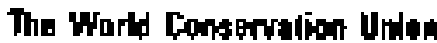

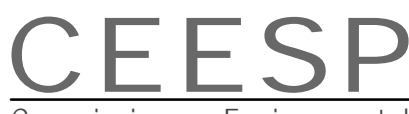

Commission on Environmental Economic and Social Policy 


\section{Governance and globalisation}

(continued from page 1)

least mobile lose out, i.e., natural resources lose out against workers, and workers lose out against capital. Consumption, of course, also goes global, as culture becomes more uniform, and as production spreads world-wide. Consequently, companies which produce these new global goods and services increasingly merge, and turn the planet into one big supermarket. Such concentration can now be found in all sectors, some of which are already highly cartelised as a result of economic globalisation.

Ecology has also become globalised. Since the beginning of the 1980s, favoured by a new scientific approach called 'Global Change' (Malone \& Roederer, 1985) the planet has increasingly been seen as a single global system (Sachs, 1993). As a consequence, many ecological issues and problems are seen as a threat to the entire Biosphere. This is now the case with nuclear pollution, climate change, ozone depletion, biodiversity destruction, and many other resource- or pollution-related issues. The actors of this new global ecological awareness can be found in the scientific community, among international environmental NGOs, and indigenous peoples' organisations (Tamiotti \& Finger, forthcoming).

Even the military, traditionally very much tied to the nationstate, has become globalised, parallel to planetary security concerns, some of which are now of a non-military nature.

In each of these five dimensions of globalisation there are new actors emerging for whom the playing field is now the entire globe. Until recently, transnational corporations (TNCS) were considered to be the most typical such new global actors (e.g., Barnet \& Cavanagh, 1994; Korten, 1995). Some of them - with their strategic vision, their mobility, and their economic and sometimes even political power - have already become more powerful than many governments. However, this same phenomenon of globalisation also extends to civil society (Princen \& Finger, 1994) in the form of 'multinational' non-governmental organisations (NGOs). In addition, new global agencies have emerged which are no longer controlled directly by governments as in the case of most UN agencies, the Bretton Woods institutions, such as the GATT and the World Trade Organisation (WTO), the International Monetary Fund (IMF), or the World Bank (Chossoudovsky, 1994; Danaher, 1994). These players not only have a global strategic vision, but are among the most active promoters of globalisation, profiting from the continuation of the nrocess.
At the level of society, there are also many victims of the same process, in particular those who are least mobile socially, geographically and professionally. At an ecological level, the first victims of globalisation are the species and people who depend directly on natural resources for survival. On a cultural level we are arguably all victims of globalisation, since for most of us, our identity remains linked to a geographical location with a given culture and language. Globalisation, on the other hand, has become synonymous with a loss of roots, loss of meaning and identity.

In short, while globalisation builds on historical trends of rationalisation, institutionalisation, expansion and further socio-cultural and ecological degradation and exploitation, it now seems to have reached a new stage in the form of new and institutionalised global organisations (TNCs, NGOs, multilateral organisations). This new global institutional reality is, however, paralleled by a corresponding process of localisation, characterised mainly by its defensiveness and reactiveness.

\section{What future for "old politics"?}

The question now is what role do traditional political players - national and local governments, international institutions, public administrations, public enterprises, political parties, and many others more - play in the new framework.

For the nation-state, the historical unit within which collective problems have traditionally been addressed, this is a particularly paradoxical situation. The nation-state was, and to a certain extent still is, a significant player in all five processes of globalisation: cultural homogenisation, ecological destruction, techno-scientific advancements (often tied to the military), military conquest, and of economic growth and industrial development more generally. Today, it seems, the same nation-state, after having loy- ally served industrial development and its promoters, has been made obsolete by the very process it has actively promoted. And in some cases, if one reads neo-liberal literature, the nation-state is now the key obstacle to further growth and economic expansion. If the winners of globalisation want to do away with the nation-state, the losers, instead, seem to put all their hopes in it. Indeed, many peoples, especially in the developing countries, seem to think that the same nation-state, which at least in part has caused their hardships, will now protect them from the negative effects of globalisation.

It is probably premature to say exactly where the nation-state is heading as a result of the numerous attempts to adapt to and cope with globalisation. However, it is possible to identify four types of pressure imposed on the nation-state by globalisation. As profits increasingly globalise and social and environmental costs increasingly localise, the nation-state runs into a structural financial problem, where it inevitably has do more with less. Secondly, there is a growing crisis of legitimacy as global actors increasingly dictate what nation-states should do (either by bypassing or by instrumentalising them), and society increasingly has reactive, defensive, and therefore temporary demands. Along with the structural financial problems, the state's declining credibility in turn leads to a loss of political coherence and collective problem-solving capacity.

Over the past ten years or so many new collective problem-solving mechanisms, along with corresponding institutions, have emerged - a phenomenon described by the concept of 'anvernance' 
In the literature of political science, the idea of governance involves a broad range of concepts. Nevertheless, four dif ferent schools of thought can be identified, namely structural or good governance, regime theory, common property resources management theory, and the idea of so-called 'global governance'.

\section{Structural or 'good governance'}

Structural governance is a tendency that involves mainly the democratic structures of a state at a national level only. In this context, the term of governance has been mainly used by the World Bank since the early 1990s. World Bank working papers usually refer to the more eloquent concept of 'good governance', introduced to address politically sensitive questions regarding state reform in developing countries, which were promoted in the main by international financial institutions. While the statutes of organisations, such as the World Bank and the IMF, expressly forbid them to take up political issues, the use of the concept of governance has allowed these institutions to interfere in political and social issues without directly confronting the governments concerned. The World Bank has used the concept of good governance in a didactic manner, mainly in Africa to determine the institutions and political practices that would be necessary for the (industrial) development of a given country (Senarclens, $1998: 92$ ), in other words in order to obtain structural adjustment loans.

The concept of good governance has also been used in the same way within the UNCED process with the aim of creating a political climate suitable for so-called sustainable development. In this context, governance came to be defined as three things: the participation of states in international law-making; the evolution of the decision-making mechanisms of international institutions; and the participation of non-governmental entities in national and international decision-making and implementation processes. In both the World Bank and the UNCED context the notion of (good) governance appears to be very close to that of government, albeit with additional participation by selected non-governmental organisations (both business and not-for-profit). Moreover, it refers to broadly accepted structures of government, whose aim it is to define a certain way of operating state institutions, usually modelled after Western democra- becomes a model able to provide non-democratic or stateless countries with appropriate democratic institutions. But it does not address the interdependency and complexity of governance situations

\section{Regime theory}

Because of an increase in the number of international institutions, the growing interdependency and complexity of local and global issues, and the emergence of new players on the international scene, it became necessary during the 1990s to redefine international public action. It is in this context that the concept of governance has been re-introduced mainly to describe interdependencies and complexities involved in the operation of a given community or institution, generally limited to a geographical area and even to a specific issue (such as, for example, polar bears) or resources (e.g., water). The idea is not to focus on the operation of structures, but rather to understand the forces and powers involved in the overall process governing the issue in question. In the context of international relations theory, the concept of area-specific governance has been used at two levels, regime theory above state level and Common Property Resources Management Theory below the state level.

Regime thinking has initiated a new trend in consideration of international institutions. The classic definition of an international regime is a set of "principles, norms, rules and decisionmaking procedures around which actors' expectations converge in a given issue area". Consequently, regimes are centred on nationstates, even though they can and often do involve other players when it comes to their formulation, implementation, and evaluation. In other words, Regime Theory pertains to a specific issue generally located at the supra-national level, often involving the solution of a specific collective problem by means of the co-operation of nation states and other players. Such a work, most often an international convention.

A number of scholars have focused their studies on the effectiveness of international regimes, where effectiveness can be defined as the degree to which international environmental accords and organisations lead to changes in behaviour that help solve collective problems. However, the assessment of the effectiveness of an international accord or regime is generally rather difficult to establish, in the same way as is the effectiveness and corresponding evaluation of public policies at the national level. The nature and extent of international environmental commitments have been transformed in recent years as states have taken on more responsibilities under treaties and agreements which are increasingly stringent and with which they must comply.

\section{Common property resources management theory} Common property resources can be broadly defined as those in which a group of people have co-equal rights, specifically rights which exclude the use of these resources by other people (World Bank, 1992). Common Property Resources Management Theory (CPRMT) looks at the ways in which individuals and groups organise themselves to govern and manage common property resources. Furthermore, it seeks to contribute to the elaboration of a theory of self-organisation and selfgovernance in a specific area, generatly related to specific resources (e.g., forests, water, fisheries, etc.) (Ostrom, 
CPRMT takes a stakeholder approach, where each stakeholder is directly affected by what the others do. It also makes very specific assumptions about the nature of the stakes. While theoretically and conceptually very solid, it is difficult to extrapolate CPRMT beyond the local level, beyond the area of natural resources, and beyond some basic assumptions about stakeholder interests.

\section{Global governance}

Global governance is certainly the most prominent, but also the vaguest use of the term governance. It is rooted in the idea that economic and financial globalisation have profoundly redistributed economic and political power, thus challenging State authority. Since the 90s, the development of humanitarian interventions has altered the previous basis of inter-state order, allowing for supra-state players to increasingly interfere in national and local matters. These and other changes have been conceptualised, albeit not systematically, by the Commission on Global Governance, meeting on a regular basis in Geneva since 1992. In a report entitled Our Global Neighbourhood, the Commission defined the concept of governance as follows:

"Governance is the sum of the many ways individuals and institutions, public and private, manage their common affairs. It is a continuing process through which conflicting or diverse interests may be accommodated and co-operative action may be taken. It includes formal institutions and regimes empowered to enforce compliance, as well as informal arrangements that people and institutions either have agreed to or perceive to be in their interest" (Commission on Global Governance, 1995).

Such a definition encapsulates almost everything, from the notion of individuals working together to that of co-operation among nation-states. Typical of UN - and particularly UNCED - jargon, this conceptualisation does not take into account the power differentials between individuals and insti tutions, or their strategic interests. By enlarging the concept of global governance to include grassroots players and local peoples, a number of authors have elevated civil society players to global players, thus not only confusing levels, but moreover ignoring the status and role of institutions. This, however, is not to say that local levels and actions are not relevant when it comes to dealing with concrete issues and day- organisations now increasingly transfer their capacity to implement to local players (Tamiotti \& Finger, forthcoming). This may have less to do with an emerging global civil society than with yet another instrumentalisation of the local by the global, furthermore bypassing nation-states in the process. In no way can such civil society activities be conceptualised as an organised counter-force to newly emerging global players.

The four conceptualisations of governance mentioned here all have their shortcomings, Good Governance Theory being particularly non-original, as it confuses governance with (American style) government. Global Governance Theory is closer to wishful thinking than to actual reality: civil society and corresponding civil society NGOs cannot be seen as being on an equal footing with other newly emerging global actors, such as TNCs and multilaterals. Moreover global governance is particularly a-political, and in this respect a typical outcome of the UNCED public relations exercise (Chatterjee \& Finger, 1994). Common Property Resources Management Theory is conceptually very sound, but deals mainly with natural resources management at a sub-national level. As such, it does not really address the issue of institutions and organised players and their interests. Regime Theory is, in my view, the most interesting and promising approach to governance, as it identifies the supra-national level and explicitly addresses the issue of organisations and institutions. However, Regime Theory refers to sectoral issues, and does not really constitute a comprehensive approach. Furthermore, it remains very state-centric. Finally, all four governance theories focus on one policy level without relating it to all other levels.

\section{Global governance: money and power}

The main players involved in collective problemsolving at the global level are governments, international and multilateral institutions, TNCs, development, trade (liberalisation and re-regulation), and security.

The past fifty years have been characterised by the expansion of international institutions and public players, carrying out international policies, some of which are self-attributed. They include the United Nations system with its various agencies, the Bretton Woods institutions, i.e., the World Bank and the International Monetary Fund, and the General Agreement on Trade and Tariffs, leading in 1995 to the creation of the World Trade Organisation (WTO). All three types of institutions developed in parallel over the past 50 years, sometimes with overlapping missions and activities. While the United Nations, with its multiple agencies, has become more and more fragmented and thinly spread (which became particularly problematic when funds got scarce), the Bretton Woods institutions, especially the World Bank, have invaded UN development territory by subsuming social development and sustainability into their economic development agenda. The GATT, on the other hand, developed a powerful dynamic of trade liberalisation, and by doing so, somewhat undermined the agendas of both the UN and the Bretton Woods institutions.

Today, in the era of economic, ecological, cultural, and technological globalisation, with their emerging problems, paralleled by the growing importance of TNCs and NGOs, these international public players have largely redefined themselves and regrouped around three key issues: security, sustainable development and trade regulation.

The UN, under heavy financial pres- 
of security, the safeguard of international boundaries, human rights protection, and humanitarian intervention. In doing so, the $\mathrm{UN}$ is abandoning one of its core mandates, development - this is being taken over by the Bretton Woods institutions, especially, the World Bank, which is in a more favourable financial position and is sensitive to public opinion. Indeed, the World Bank, UNDP (the UN Development Programme), and UNEP (the UN Environment Programme), already linked through the GEF (Global Environmental Facility), seem to be regrouping around the issue of sustainable development, and this might well lead up to a new 'Earth Bank'. Finally, there is the issue of trade and trade regulation. Having actively promoted trade liberalisation, the GATT and the WTO now increasingly come under pressure from public opinion, developing countries, and TNCs, asking for the reintroduction of some sort of trade regulation. In order to do this, however, the WTO will have to regroup with organisations such as ISO (the International Standardisation Organisation), and other private players. This illustrates that, at the global level, the definition of future governance mechanisms is driven by financial and economic interests as well as corresponding power, mainly of TNCs. As a result, privately defined standards are likely to become perfectly acceptable tools for global trade regulation.

The environment, as a cross-cutting issue, relates to all three dimensions - security, sustainable development and trade regulation. Indeed, environmental degradation has become an issue of security. Examples are found in the potential conflicts arising from scarcity of natural resources (such as water), or from transnational environmental damage (such as nuclear disasters). Secondly, since UNCED, environmental protection has been reframed in terms of 'sustainable development', and UN bodies, such as the UNDP and the World Bank, have been keen to promote corresponding (sustainable) development projects. The environment also pertains to trade: while environmental protection was and still is considered to be an impediment to trade, it is also becoming an argument, or perhaps an excuse, for re-regulating trade.

\section{National governance: managing networks}

It is of course at the national level where governments still have the strongest hold on public affairs. Nevertheless, even there one can observe the erosion of traditional politics, both in terms of the policy process (policy-formulation, policy implementation, and compliance) and in terms of public management where more and more stakeholders are involved. In parallel, one can observe how new types of policies - i.e., facilitating, enabling, incentive-based, etc. - are made necessary since traditional 'command and control' policies are no longer effective. As a result, various stakeholders - e.g. businesses and NGOs - are being included both in the definition of the (environmental) policies and their implementation.

This is not (yet) comparable to the situation at the global level, where governments are clearly only one among many players involved in managing public affairs. In this respect, the term governance at the national level is not entirely appropriate. Governments retain their ultimate power, i.e., sovereignty over their territory, as well as control over legislation. Nevertheless, the capacity to get things done is increasingly dependent upon a government's ability to mobilise the various players involved.

None of the above governance theories addresses this issue at the national level. One has to look at theories of public management to find a conceptualisation of this development. If the public service in question can be delivered for the most part by the market, there is a clear trend from public service provision to regulation. Where this is not the case, i.e., when public service is mainly the result of public provision, one can identify new theoretical conceptualisations such as "network management". Here the role of government is to mobilise and facilitate a complex network of public, private, and not-for-profit players. Unfortunately, such conceptualisations are never fed into the larger framework of governance, nor related to developments occurring above and below the nation-state level.

\section{Local governance}

At the local level, governance is a totally different matter. In the era of globalisation, the local becomes synonymous with exploitation and domination, where it is used by the global to further the process of globalisation. The local is where problems first become visible - even if they are only symptoms of global problems and where they need to be solved as they arise, but it is also where the resources and means to address such problems are scarcest. If these problems become too overwhelming, national and global players intervene.

In non-crisis situations, national politics generally defines the local as the level at which all global, regional and national policies will ultimately (have to) be implemented. It is also the level which gives legitimacy to the entire public poricy chain. Many collective issues may be handled more efficiently at the local level as populations often have intimate knowledge and experience of local ecosystems, as well as a sense of continuity with a given place.

This level of governance has only been recognised in the context of larger global problems, in particular after the publication of the Brundtand Report in 1987. The need for and the role of local actions has been enhanced by Agenda 21, agreed to at UNCED, and which led to a spate of local initiatives throughout the world. Such local initiatives, however, are rarely self-contained local governance mechanisms, as they are part of a larger concept of implementing a 'global public policy'.

True local governance is something else, namely community-based local problem-solving within the larger framework of globalisation and localisation as outlined above, and of 'learning our way out' of the dead end of 
industrial civilisation (e.g., Finger \& Asún, forthcoming). Such collective problem-solving efforts will become increasingly necessary parallel to the process of globalisation and the destructive effects it has on local communities and their livelihoods. They are also quite different from the efforts conceptualised by Common Property Resources Management Theory. Indeed, the weakness of that theory lies in the fact that it does not contextualise common property resources management, particularly within the larger framework of globalisation, although this is where the most innovative governance efforts take place.

Governance efforts as I have defined them above, can be seen as attempts to solve (public) problems collectively by identifying the relevant stakeholders - and can be identified at global, national, and local levels. Even though the stakes, and often the players involved are different at each of the three levels of governance, the levels are not independent from another, but nor are they at all co-ordinated.

This is particularly problematic in the case of the four theories discussed above, which all focus on their specific levels. Global Governance Theory maintains the illusion that governance can be an encompassing concept linking the local, the national, and the global into one coherent governance framework. As such, Global Governance Theory - along with Common Property Resources Management Theory - leads one to believe that all the players involved in a given governance mechanism are equal partners, deciding about their common fate and/or the use of their resources. In this respect, all four governance theories are particularly pernicious: they hide power relationships and the players' strategic interests. This is particularly problematic at the global level.

Global players now have a significant advantage over local and even national players, as they are more mobile and often richer. As a result, they exploit the local, particularly the local resources and manpower, by playing them against each other. Increasingly, the global players, mainly the TNCs, also exploit nation-states, or nation-states are simply instrumentalised in order to better exploit the local. If the national cannot be instrumentalised by the global players - say for example by the multilateral institutions - it is simply bypassed, as in the case of the World Bank which works directly with northern and southern NGOs when it comes to implementing some of its ohiectives.

\section{A comprehensive approach to governance}

It is doubtful whether any of these three levels is the appropriate one when it comes to dealing with globalisation and its negative consequences: indeed the global level is too interested and involved in pursuing the process for it to be an appropriate level to address it. The nation-state, in turn, is either already too instrumentalised by the global actors or simply not the appropriate level when it comes to addressing the main problems caused by globalisation, such as the cultural and the ecological consequences of globalisation, in particular, but probably also the economic problems. The local level, in turn, even though the most innovative one, is probably too small and too vulnerable to national and global forces.

One therefore has to think of other levels of governance when it comes to addressing the negative consequences of the globalisation process. Key requirements for such levels to be relevant pertain, in my view, to some sort of ecological integrity or coherence (e.g., bio-regionalism, eco-regions, watersheds, etc.), but also to some sort of cultural dimension. The main stake in the age of globalisation, pertains to ecological and cultural survival. Despite the wealth of literature on eco-regions, the cultural aspect still has to be clarified. Nevertheless, both the ecological and the cultural dimensions point to a regional approach to governance, which, depending on the country and the region, can either be of supra- or of sub-national nature. There is yet another advantage to defining governance at such a regional level, as most of the governance mechanisms can still be designed, as opposed to having to be reclaimed. The original strategy of the 'new politics' thus would precisely be in the design of such new regional governance mechanisms.

In the design of such regional governance mechanisms, one could certainly be inspired by Regime Theory, as well as by Common this conceptualisation would have to occur within the larger context of the globalisation-localisation dynamics, taking into account the respective powers and strategic interests of the various global and national playerrs. Finally, such a conceptualisation would have to locate itself within the overall framework of collective problem-solving or 'learning our way out' (Finger \& Asún, forthcoming), the main issue being the level at which such collective problem-solving makes most sense and has most autonomy.

\section{Bibliography}

Barnet, R. \& J. Cavanagh (1994). Global Dreams. Imperial corporations and the new world order. New York: Simon and Schuster.

Chatterjee, P. \& M. Finger (1994). The Earth Brokers. Power, politics and world development. London: Routledge.

Chossoudovsky, M. (1997). The globalisation of poverty. Impacts of IMF and World Bank reforms. London: Zed Books.

Commission on Global Governance (1995) Our Global Neighbourhood. Oxford: Oxford University Press

Danaher, K. (1996). Corporations are gonna get your mama. Globalization and the downsizing of the American Dream. Monroe ME: Common Courage Press.

Dunning, J.H. (1993). The globalization of business. London: Routledge.

Korten, D. (1995). When corporations rule the world. West Hartford CT: Kumarian Press.

Malone, T.F. \& J.G. Roederer (eds.) (1985). Global Change. Cambridge University Press. Ostrom, E. (1990). Governing the Commons. The Evolution of Institutions for Collective Action. Cambridge: Cambridge University Press.

Princen, T. \& M. Finger (eds.) (1994). Environmental NGOS in World Politics.: Linking the Local to the Global. London: Routledge. Ritzer, G. (1998). The McDonaldization Thesis. London: Sage.

Sachs, W. (ed.) (1993). Global ecology: a new arena of political conflict. London: Zed Books. Senarclens, P. (1998). "Governance and the crisis in the international mechanisms of regulation". International Social Science Journal 155. World Bank (1992) Governance and development. Washington D.C.: World Bank

Matthias Finger is Professor at the Institute for Advanced Studies in Public Administration, Lausanne, Switzerland, and the Institute for Social Ecology, Plainfield, 